\title{
Adult Acute Lymphoblastic Leukemia in Remission
}

National Cancer Institute

\section{Source}

National Cancer Institute. Adult Acute Lymphoblastic Leukemia in Remission. NCI

Thesaurus. Code C7937.

Acute lymphoblastic leukemia in adults which is not growing and responds to treatment. 